\title{
A survey of phenotypic features in juvenile polyposis
}

Devendra C Desai, Vicky Murday, Robin K S Phillips, Kay F Neale, Peter Milla, Shirley V Hodgson

\begin{abstract}
Solitary juvenile polyps are quite frequent in children, but juvenile polyposis (JP) is a rare autosomal dominant trait characterised by the occurrence of numerous polyps in the gastrointestinal tract. Extracolonic phenotypic abnormalities are well documented in patients with familial adenomatous polyposis and Peutz-Jeghers syndrome and can allow a clinical diagnosis to be made before the bowel pathology becomes available. Though described, characteristic extracolonic abnormalities have not been clearly defined in juvenile polyposis. We sought to determine whether there are consistent extracolonic phenotypic abnormalities in JP patients and how frequently this would allow diagnosis of one of the genetic syndromes known to be associated with juvenile polyposis.
\end{abstract}

Twenty-two JP patients underwent clinical examination and data from one patient were obtained from case notes. Those consenting to further investigations had $x$ rays of the skull, chest, and hands and an echocardiogram if clinically indicated. Significant extracolonic phenotypic abnormalities were present in 18 patients (14 male and four female), and included dermatological (13), skeletal (16), neurological (5), cardiopulmonary (4), gastrointestinal (3), genitourinary (4), and ocular (1) features. In five patients the diagnosis of a genetic syndrome was possible: two had Bannayan-RileyRuvalcaba syndrome, two had Gorlin syndrome, and one had hereditary haemorrhagic telangiectasia (HHT, also known as Osler-Rendu-Weber syndrome). Other patients had some features of these conditions and of Cowden and SimpsonGolabi-Behmel syndromes, but these were not sufficient to allow a definitive diagnosis.

(F Med Genet 1998;35:476-481)

Keywords: juvenile polyposis; Cowden syndrome; Gorlin syndrome; Bannayan-Riley-Ruvalcaba syndrome

Juvenile polyposis (JP) is an uncommon autosomal dominant condition characterised by hamartomatous polyps, usually in the colon but sometimes in the stomach and small bowel. ${ }^{1}$ These polyps have an abundant lamina propria lacking smooth muscle (differentiating them from Peutz-Jegher polyps, which do contain smooth muscle) and have malignant potential. $^{1-8}$ Extracolonic features have been reported in association with JP, but the exact proportion of affected subjects with such abnormalities has not been ascertained. ${ }^{19-11}$ Juvenile polyps may occur as a feature of a number of genetic syndromes, including Bannayan-Riley-Ruvalcaba syndrome (characterised by macrocephaly, mental retardation, and pigmented spotting of genitalia ${ }^{62-14}$ ), Cowden syndrome (a multiple hamartoma syndrome characterised by hamartomas of multiple organs, macrocephaly, trichilemmomas, and thyroid and breast disease, leading to a high cancer risk in these organs ${ }^{15}$ ), and Gorlin syndrome (an autosomal dominant condition characterised by multiple naevoid basal carcinomas, odontogenic keratocysts, skeletal abnormalities such as macrocephaly, hypertelorism, rib and vertebral anomalies, short metacarpals, pits in the skin of the palms and soles, and intracranial calcification ${ }^{12}{ }^{16}$ ).

The aim of this study was to determine the prevalence of extracolonic abnormalities in JP, and to determine the possible contribution of genetic syndromes to the aetiology of this condition. Molecular tests for germline mutations in the genes underlying the conditions diagnosed in our patients are becoming available, and we have some preliminary data about this, but further studies are required.

\section{Materials and methods}

DIAGNOSTIC CRITERIA

We took as our criteria for the diagnosis of juvenile polyposis any one of the following: (1) three or more colonic juvenile polyps; (2) juvenile polyps throughout the gastrointestinal tract; (3) any number of juvenile polyps in a patient with a family history of juvenile polyposis. $^{17}$

PATIENTS

Patients were ascertained through the St Mark's Hospital Polyposis Registry, The Hospital for Sick Children, Great Ormond Street, and Guy's Hospital, London, and via a questionnaire circulated to geneticists and pathologists, and in a mailing to the members of the British Society of Gastroenterology. Only two patients (Nos 4 and 5), identified at St Mark's Hospital, had already been given a provisional diagnosis of one of the syndromes discussed.

A questionnaire was completed for each affected subject, providing details including symptoms, investigations carried out, and treatment received. An approach to the doctors concerned was made whenever it was necessary to 


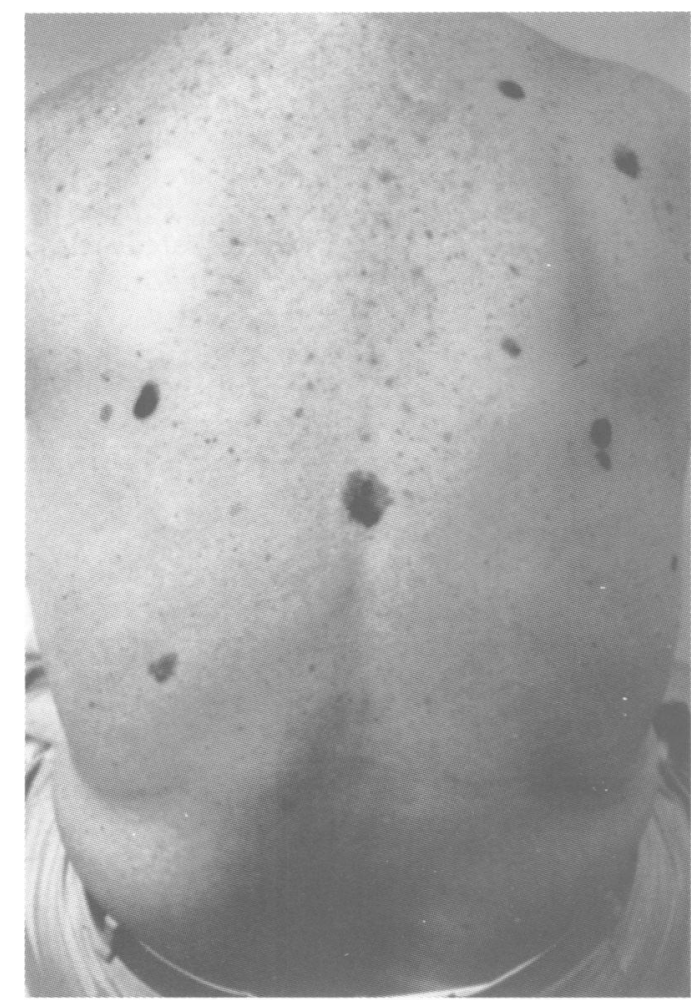

Figure 1 Multiple basal cell lesions (seborrhoeic keratosis) in patient 1. These lesions are benign per se, but this patient had a history of basal cell carcinoma.

clarify any clinical details, and patients were examined clinically for extracolonic phenotypic abnormalities. The following measurements were recorded for each patient where possible: occipitofrontal circumference, distance between inner canthi, and distance between outer canthi. Those patients consenting to further investigations underwent $x$ rays of the chest, skull (anteroposterior and lateral views, includ- ing the jaw), and hands. Patients in whom clinical examination was suggestive of a cardiac abnormality underwent an echocardiogram.

Blood was obtained from some cases with informed consent for testing for germline mutations in candidate genes.

\section{Results}

Twenty-two patients were seen clinically and in one patient data were obtained only from case notes. Thus a total of 23 patients were included, $x$ rays being performed in 14 . Seventeen were male and six female, with a median age of 29 years (age range 4-65 years).

Patients 7 and 8 were brothers, patients 9 and 10 were from the same family, and patients 12 and 16 were mother and daughter. All other cases were sporadic. Extracolonic phenotypic abnormalities (table 1) were detected in 18 of the 23 patients $(78 \%)$. Dermatological abnormalities (including telangiectases and large numbers of pigmented naevi) were common (13 patients), as were skeletal abnormalities (16 patients). Other abnormalities included neurological (five patients and one patient with epilepsy), gastrointestinal (three patients) and cardiac abnormalities (three patients), undescended testes (four patients), and ocular abnormalities (one patient).

Increased numbers of pigmented naevi were common (fig 1), followed by telangiectasia of the skin and mucous membranes, cutaneous and subcutaneous swellings, and skin pits on the fingertips. One patient had a basal cell carcinoma.

Hypertelorism (13 cases) and macrocephaly (nine cases) were the commonest skeletal abnormalities present, and broad hands (fig 2),

Table 1 Phenotypic abnormalities in 18 patients

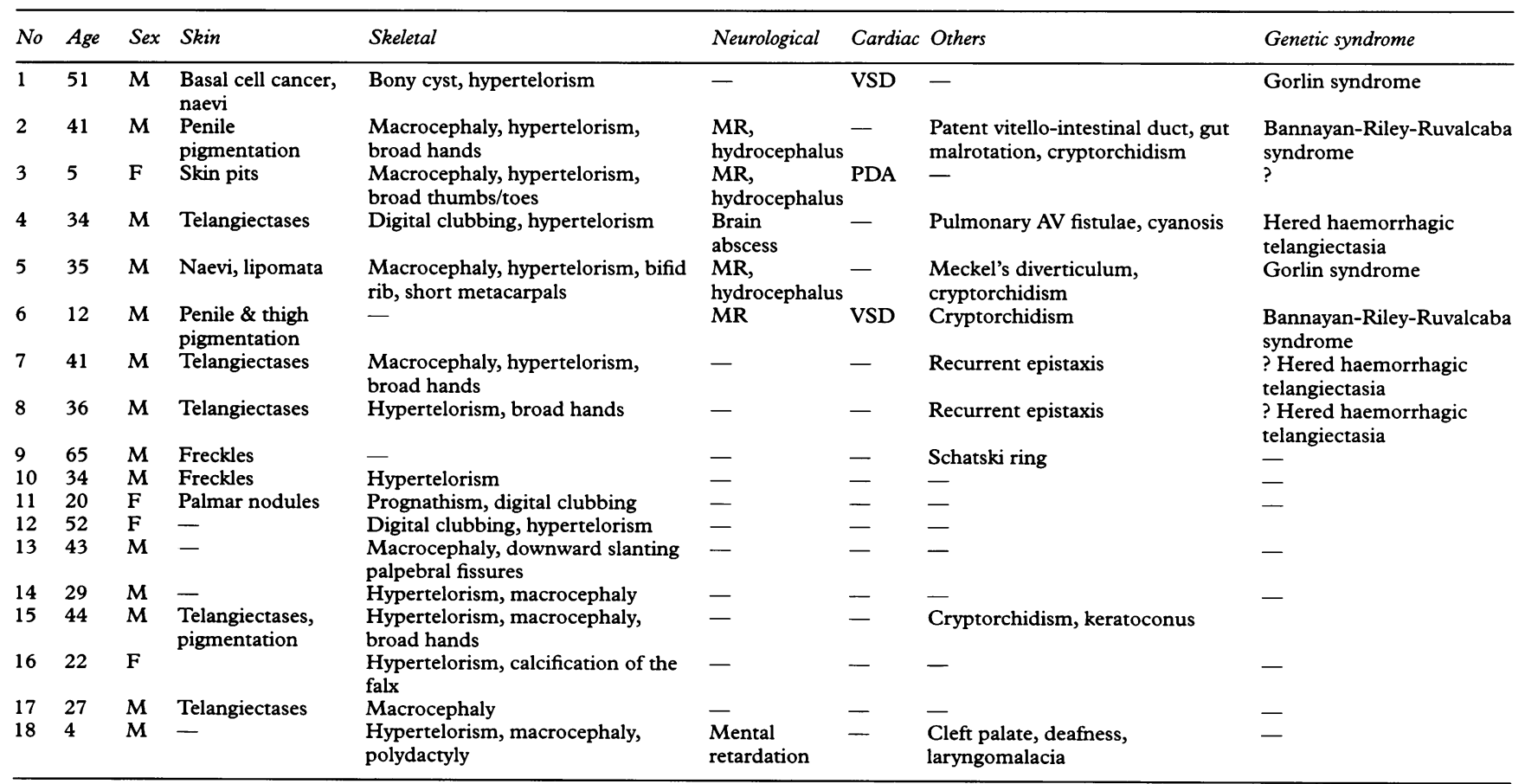

VSD = ventricular septal defect, $P D A=$ patent ductus arteriosus, $M R=$ mental retardation

Patients 7 and 8 were two affected brothers.

Patients 9 and 10 were from one family.

Patients 12 and 16 were mother and daughter. 


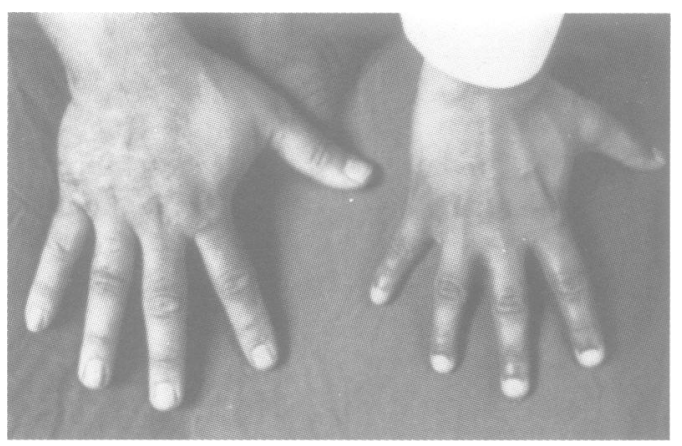

Figure 2 Broad hands (as compared to normal) in patient 5, who had features of Gorlin syndrome. This patient also had hydrocephalus, mental retardation, bifid rib, and multiple lipomas and naevi.

digital clubbing, and prognathism were also seen. One patient had polydactyly and a cleft palate.

Of the six patients with neurological abnormalities, five were mentally retarded and one had a cerebral abscess. The diagnosis of mental retardation was based on delayed developmental milestones and neurological evaluation. Three patients with mental retardation had undergone a CT scan, and all three had a diagnosis of arrested hydrocephalus. Two of these patients (children) require special schooling for mental retardation, and two others (adults) need constant parental help. The patient with a cerebral abscess (patient 4, described below) was later diagnosed as having HHT with pulmonary arteriovenous (AV) fistulae (fig 3), and the cerebral abscess was thought to be the result of paradoxical embolism. One patient, who had no phenotypic abnormalities, was epileptic.

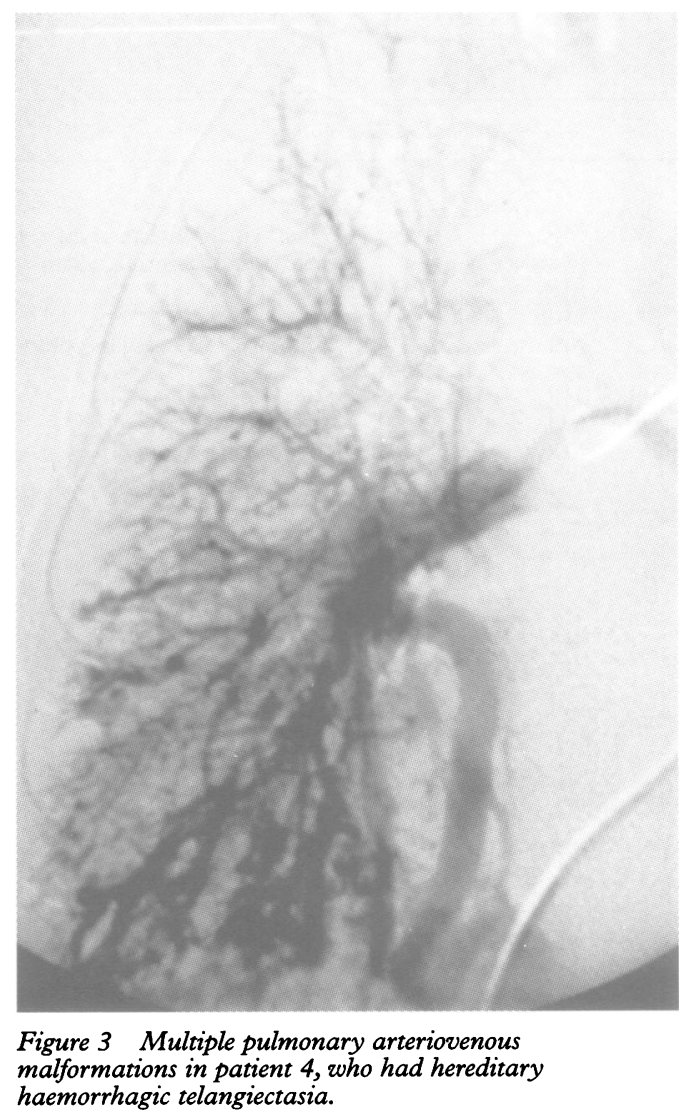

Two patients had a ventricular septal defect which closed spontaneously. Patient 3 had a patent ductus arteriosus (PDA) related to prematurity, which closed following administration of indomethacin. She had required respiratory support for four weeks after birth. She presented with severe anaemia, rectal bleeding, and a protein losing enteropathy at the age of 3 years, and underwent colectomy a year later. Her echocardiogram at the age of 5 years showed pulmonary hypertension with mild tricuspid and pulmonary regurgitation. The pulmonary hypertension was thought to be the result of upper respiratory tract obstruction.

Patient 4, who had JP and HHT, presented with digital clubbing, cyanosis, and multiple skin and mucous membrane telangiectases. His oxygen saturation was low $(70 \%)$ and a pulmonary angiogram showed multiple bilateral AV fistulae which were embolised with resulting clinical improvement.

Patient 18, who had polydactyly and a cleft palate, presented with a protein losing enteropathy and had laryngomalacia and congenital deafness. One patient had a Meckel diverticulum, one had a patent vitellointestinal duct with malrotation of the gut, and one had a Schatski ring which required dilatation. Four patients had cryptorchidism. One patient had bilateral keratoconus.

Five unrelated patients had features diagnostic of well defined genetic syndromes: Bannayan-Riley-Ruvalcaba syndrome in two, Gorlin syndrome in two, and HHT in one. Patients 2 and 6 had features of BannayanRiley-Ruvalcaba syndrome: both had pigmented macules, 4-5 $\mathrm{mm}$ in diameter, either on the glans penis alone (patient 2 ) or on the glans and shaft of the penis and the inner aspect of the thighs (patient 6). Patient 2 had macrocephaly and an occipitofrontal circumference (OFC) of $67 \mathrm{~cm}$ (2 SD above the normal upper limit, which is $60 \mathrm{~cm}^{9}$ ); patient 6 had an OFC of $55 \mathrm{~cm}$. Both were also mentally retarded, which completed the diagnostic triad for the condition.

The diagnosis of Gorlin syndrome in patient 1 was based on the presence of multiple basal cell naevi, a basal cell carcinoma, and the presence of a bony cyst in a metacarpal. In patient 5, multiple naevi, lipomas, a bifid rib, macrocephaly, hypertelorism, hydrocephalus, and mental retardation were present. Neither of these patients had intracranial calcification or odontogenic keratocysts.

Patient 4, who suffered from HHT and pulmonary AV fistulae, is described above. In addition, patients 7 and 8, who were brothers, had skin and mucous membrane telangiectases, and recurrent epistaxis since childhood, for which one had required laser photocoagulation of the $\mathrm{AV}$ malformation in the nasal cavity. They thus had some features of HHT, but not sufficient for the diagnosis of the condition to be made, since no pulmonary or gastrointestinal lesions were apparent.

Patient 3, who had skin pits and hydrocephalus, and patient 18 , who had macrocephaly and polydactyly, did not fulfil all the criteria for the 
diagnosis of any of the syndromes considered above, but did have several dysmorphic features consistent with Gorlin syndrome; the latter's features were also consistent with a possible diagnosis of Simpson-Golabi-Behmel syndrome. Patient 16, with hypertelorism and calcification of the falx cerebri, also had some features of Gorlin syndrome, in which falx calcification is a characteristic feature.

Preliminary studies have been arranged to test for germline mutations in the known genes for HHT in patients 4,7 , and 8 and no mutations have been detected to date.

Patients 7, 8, 9, 10, 12,13,14, 16, and an affected male with no phenotypic abnormalities were included in a recent study in which germline mutations in PTEN (see below) were sought in patients with JP and no mutations were detected. ${ }^{18}$ These studies are continuing.

\section{Discussion}

The characteristic juvenile polyps found in JP have been described as a feature of several distinct genetic syndromes. However, there has been very little attempt in the past to diagnose these patients from the genetic standpoint. Information about extracolonic abnormalities in juvenile polyposis is mainly in the form of isolated case reports and tends to be descriptive. Reported abnormalities have included digital clubbing, hypertrophic pulmonary osteoarthropathy, arteriovenous malformations, alopecia, porphyria, psoriasis, macrocephaly, supernumerary teeth, mental retardation, congenital heart disease, cleft lip/palate, malrotation of the gut, bifid uterus and vagina, undesended testes, and umbilical hernia, all in association with juvenile polyposis in individual cases. ${ }^{19-11} \mathrm{~A}$ recent review reported an $11 \%$ incidence of extracolonic abnormalities in juvenile polyposis. ${ }^{1}$ In the present study, we have found that the incidence is much higher than this, since extracolonic abnormalities were detected in $78 \%$ of our patients with juvenile polyposis. This is particularly striking since not all the patients consented to investigation, and only in two had a diagnosis of one of the syndromes discussed here been entertained. In 11 of the patients we studied, the phenotypic abnormalities were clinically important, and included skin cancer, mental retardation, cardiac anomalies, arteriovenous malformations, undescended testes, cleft palate, keratoconus, Schatski ring, abnormality of the vitellointestinal duct, malrotation of the gut, and laryngomalacia. Nearly one fifth of the patients were mentally retarded, and a CT brain scan detected hydrocephalus in three patients.

Although the cardiac anomalies in these patients did not require surgical treatment, it is important to recognise them, since JP patients are likely to undergo multiple endoscopies and hence could be at risk for infective endocarditis. The occurrence of a cerebral abscess in a patient with pulmonary AV fistulae underlines this point.

It is of interest that only $26 \%$ of the cases we ascertained (and $22 \%$ of those with phenotypic abnormalities) were female. A similar excess of males has been noted previously (3:1 male preponderance $\left.{ }^{6}\right)$. There is no obvious reason why this should be the result of ascertainment bias, although with such small numbers this may be not a significant finding. However, this male preponderance could be because of sex dependent expression of the juvenile polyps or the contribution of sex linked conditions to the aetiology of juvenile polyposis. In this context it is notable that patient 18 does have many of the features of Simpson-Golabi-Behmel (SGB) syndrome, an $\mathrm{X}$ linked condition of variable mental handicap with overgrowth, macrocephaly, hypertelorism, polydactyly, rib abnormalities, and occasionally cleft palate. ${ }^{19}$ Juvenile polyps are not documented as a regular feature of this condition, but it is well known to show very variable penetrance, and since macrocephaly and hypertelorism are common features in our cases, it does beg the question as to whether the male excess of cases of JP in our series could be the result of $X$ linked conditions. Mutations in the glypican gene, GPC3, have been found to underly SGB syndrome and should allow us to test for germline mutations in this cohort.

Four of 17 male patients examined had undescended testes. This is much higher than the reported incidence of $0.8 \%$ in males older than 1 year in the general population. ${ }^{20}$

This study clearly suggests that some patients with juvenile polyposis may have genetic syndromes, such as Bannayan-Riley-Ruvalcaba syndrome, Gorlin syndrome, or HHT. Our patients with Bannayan-Riley-Ruvalcaba syndrome had macrocephaly, genital pigmentation, and mental retardation. Additional features found in patients with Bannayan-RileyRuvalcaba syndrome include lipomas (70\%), lipid storage myopathy $(60 \%)$, and haemangiomas $(10 \%) .^{112122}$ Hamartomatous gastrointestinal polyps occur in $45 \%$, while Hashimoto's thyroiditis has been described in seven patients, ${ }^{15}$ and testicular enlargement in two. ${ }^{12}$ One of our patients had cryptorchidism. Congenital heart disease has also been described in Bannayan-Riley-Ruvalcaba syndrome, and one of our patients had a ventricular septal defect. The congenital anomalies in the other patient, which included a patent vitellointestinal duct and gut malrotation, have not previously been described in patients with this syndrome.

Gorlin syndrome is a complex hamartoma/ neoplastic malformation syndrome primarily involving the skin, central nervous system, and skeletal system. ${ }^{12}$ Our patients had craniofacial, skeletal, and dermatological characteristics of this condition, but lacked some of the common features, such as skin pits and calcification of the falx cerebri. One patient had cryptorchidism, which has also been described in this syndrome. Three other patients had some features of Gorlin syndrome, one with calcification of the falx, a characteristic feature of Gorlin syndrome, one with macrocephaly and polydactyly, and one with skin pits, hypertelorism, macrocephaly, and mental retardation. Of interest in this context is a case report in 1982 of a patient with juvenile polyposis with recurrent basal cell carcinomas and two central 
nervous system tumours, but with no skin pits or calcification of the falx, ${ }^{13}$ but the supposition must be that this patient had Gorlin syndrome.

The diagnosis of HHT is usually based on a history of repeated epistaxis since childhood, the presence of telangiectases on the skin or mucous membranes, or both $(75 \%$ of patients), or involving the gastrointestinal (25\%), pulmonary $(15 \%)$, or cerebral $(4 \%)$ vessels, and a similar history in one other member of the family (parent, sib, or child). ${ }^{21}$ It is of interest that some of these criteria were present in patients 8 and 9. Patient 4 had telangiectasia and pulmonary AV fistulae, although there was no history of HHT in his parents or sibs and he had no children.

The importance of diagnosing a genetic syndrome in the context of juvenile polyposis is clear. One report suggests a $17 \%$ incidence of colorectal malignancy in cases of juvenile polyposis, ${ }^{8}$ so all patients should have endoscopic surveillance for colonic cancer because of the established malignant potential of these polyps. $^{623}$ If certain genetic conditions are likely to predispose to juvenile polyposis, clinicians should be alerted to this possibility. In addition to endoscopic surveillance in cases with JP, patients with Bannayan-RileyRuvalcaba syndrome should be followed up for Hashimoto's thyroiditis and thyroid and breast malignancies, those with Gorlin syndrome should be kept under dermatological surveillance for basal cell carcinoma and jaw cysts, and those with HHT for pulmonary and other AV fistulae.

The occurrence of juvenile polyposis with other genetic syndromes suggests genetic heterogeneity in the aetiology of JP, and may help in locating the gene or genes involved in the causation of this condition. Analysis of one large JP family has indicated lack of linkage to the APC (adenomatous polyposis coli) locus or to the nearby MCC (mutated in colorectal cancer) locus, ${ }^{24}$ while in a large family with "mixed" juvenile and adenomatous polyposis linkage to chromosome $6 \mathrm{q}$ has been shown. ${ }^{25}$

The genes responsible for those conditions in which juvenile polyposis has been described may be considered as candidate genes for JP without such obvious phenotypic features. The gene for Gorlin syndrome has been localised to chromosome 9 (9q22.3-q31), ${ }^{26}$ and has been shown to be the human homologue of the Drosophila developmental gene patched.$^{28}$ Genes for HHT have been mapped to chromosomes 9q3 (quite close to the Gorlin syndrome locus) and 12q11-14, and mutations in endoglin and the activin receptor-like kinase 1 gene, respectively, have also been detected in affected subjects. ${ }^{22}{ }^{29}{ }^{30}$ The gene for Cowden syndrome has been localised to chromosome $10 \mathrm{q}$, and mutations in the tumour suppressor gene PTEN have been detected in several affected subjects. ${ }^{31}$ Bannayan-Riley-Ruvalcaba syndrome has many similarities to Cowden syndrome, including freckling, macrocephaly, juvenile polyps, and thyroid disease, with histological similarities in hamartomatous lesions ${ }^{32}$ making PTEN a good candidate gene for this condition also. Furthermore, germline mutations in PTEN have recently been identified in affected subjects with the condition in two families, and have been found to segregate with the disease. ${ }^{33}$ The recent detection of deletion of a 10q22 tumour suppressor locus from non-epithelial cells in the lamina propria from patients with $\mathrm{JP}^{34}$ further suggests that germline PTEN mutations may cause at least some cases of JP. A constitutional deletion has been detected in chromosome 10q22.3-24.1 in a patient with JP and multiple congenital abnormalities and developmental delay, ${ }^{35}$ reinforcing the hypothesis that a gene involved in the aetiology of JP is located there, but LOH at this locus does not appear to be important in all cases of juvenile polyposis. ${ }^{18}$ The association of HHT with juvenile polyposis in a few patients raises the possibility that JP could occur as part of a $9 \mathrm{q}$ or $12 \mathrm{q}$ microdeletion syndrome in some cases. However, no mutations at either of the known HHT loci have yet been detected in our cases with features of HHT (patients 4, 7, and 8) (J Berg, personal communication).

Eight affected members of six families in this study were included in a group of JP patients investigated for germline mutations in PTEN, but no mutations have yet been detected. ${ }^{18}$ None of these patients had a clinical diagnosis of Bannayan-Riley-Ruvalcaba syndrome, but these preliminary results suggest germline mutations in genes other than PTEN may underly a proportion of cases of JP. Molecular studies will be continued on our cohort of patients.

$\mathrm{JP}$ is likely to be a heterogeneous condition, but the detection of candidate genes, PTEN and Patched, in which germline mutations may be responsible for a proportion of cases of JP, may lead to further insights into the aetiology of this disorder.

We would like to thank the Imperial Cancer Research Fund for support for the St Mark's Polyposis Registry. The author gratefully acknowledge the assistance of the following people who helped in this study: Ms Josephine Mulligan (Research Assistant) and Mr Prem Puri (Director of Research, Children's Research Centre, Our Lady's Hospital for Sick Children, Dublin); Mrs Margaret Adams (Oxford Regional Genetic Service) Ms Caroline Doig (Senior Lecturer in Paediatric Surgery, Booth Hall Children's Hospital, Manchester); Professor R A Risdon (Department of Histopathology, Hospital for Sick Children Great Ormond Street Hospital); Professor Ian Booth (Institute of Child Health, Birmingham); Mr Malcolm Dunlop (MRC of Child Health, Birmingham); Mr Malcolm Dunlop (MRC Human Genetic Registry, Western General Hospital, Edinburgh); Dr A F Muller (University of Nottingham); Professo Jeremy Jass (Department of Pathology, University of Auckland School of Medicine, Auckland, New Zealand); Professor John Burn and Mrs Pam Chapman (Northern Region Polyposis Registry, Newcastle upon Tyne); and Mr Ken Miller (Chief Scientific Officer, ICRF Colorectal Unit, St Mark's Hospital, London). Devendra C Desai was supported by the Association of Commonwealth Universities and the British Council.

1 Hofting I, Pott G, Stolte M. Das syndrom der juvenillen polyposis. Leber Magen Darm 1993;23:107-12.

2 Reed K, Vose PC. Diffuse juvenile polyposis of colon: a premalignant condition? Dis Colon Rectum 1981;24:205-10.

Rosen P, Baratz M. Familial juvenile colonic polyposis with associated colon cancer. Cancer 1982;49:1500-3.

4 Jarvinen H, Franssila KO. Familial juvenile polyposis coli increased risk of colorectal cancer. Gut 1984;25:792-800.

5 Jass JR, Williams CB, Bussey HJR, Morson BC. Juvenile Jass JR, Williams CB, Bussey $\mathrm{HJR}$, Morson BC. Juvenile
polyposis - a precancerous condition. Histopathology 1988; 13:619-30.

6 Coffin CM, Dehner LP. What is a juvenile polyp? Arch Pathol Lab Med 1996;120:1032-8.

7 Sharma AK, Sharma SS, Mathur P. Alimentary tract and pancreas. Familial juvenile polyposis with adenomatouscarcinomatous change. $\mathcal{F}$ Gastrol Hepatol 1995;10:131-4.

8 Coburn MC, Pricolo VE, DeLuca FG, Bland KI. Malignant potential in intestinal juvenile polyposis syndromes. Ann Surg Oncol 1995;2:386-91. 
9 Shepherd NA, Bussey HJR. Polyposis syndromes - an update. Curr Top Pathol 1990;81:323-46.

10 Schumacher B, Freiling T, Berchard F, Hengels KJ. Hereditary haemorrhagic telangiectasia associated with multiple pulmonary arteriovenous malformations and juvenile polyposis. $Z$ Gastroenterol 1994;32:105-8.

11 Rabin DR. Hereditary generalised juvenile polyposis: association with arteriovenous malformations and risk of malignancy. Abdom Imaging 1994;19:140-2.

12 Gorlin RJ, Cohen MM Jr, Levin LS. Syndromes of the head and neck. 3rd ed. New York: Oxford University Press, 1990.

13 Michels VV, Stevens JC. Basal cell carcinoma in a patient with intestinal polyposis. Clin Genet 1982;22:80-2.

14 Gorlin RJ, Cohen MM Jr, Condon LM, Burke BA. Bannayan Riley Ruvalcaba syndrome. Am $\mathcal{F}$ Med Genet 1992;44:307-14.

15 Foster MA, Kilcoyne RF. Ruvalcaba Myhre Smith syndrome: a new consideration in the differential diagnosis of intestinal polyposis. Gastrointest Radiol 1986;11:349-50.

16 Hizawa $\mathrm{K}$, Iida $M$, Matsumoto $T$, et al. Gastrointestinal manifestations of Cowden's disease. Review of four cases. $\mathcal{F}$ Clin Gastrol 1994;18:13-18.

17 Gorlin RJ. Naevoid basal cell carcinoma syndrome. Dermatol Clin 1995;13:113-25.

18 Marsh DJ, Roth S, Lunetta KL, et al. Exclusion of PTEN/MMAC1/TEP1 and 10q22-24 as the susceptibility PIEN for juvenile polyposis syndrome (JPS). Cancer Res (in press).

9 press)

Hughes-Benzie RM, Pilia G, Xuan AGW, et al. SimpsonGolabi-Behmel syndrome: genotype/phenotype analysis of 18 affected males from 7 unrelated families. $A m \mathcal{F} M e$ Genet 1996;66:227-34

20 Weiss RM. Congenital disorders of the scrotum and its content. In: Whitfield HN, Hendry WF, ed Textbook of genito-urinary surgery. Vol 1 . 1 st ed. Edinburgh: Churchil Livingstone, 1985.

21 Hughes JMB. Intrapulmonary shunts: coils to transplantation. F R Coll Physicians Lond 1994;28:247-53.

22 Berg JN, Guttmacher AE, Marchuk DA, Porteous ME. Clinical heterogeneity in hereditary haemorrhagic telangiectasis: are pulmonary arteriovenous malformations more common in families linked to endoglin? $\mathcal{f}$ Med Genet 1997;33:256-7.
23 Gierdiello FM, Hamilton SR, Kern SE, et al. Colorectal neoplasia in juvenile polyposis or juvenile polyp. Arch Dis Child 1991;66:971-5.

24 Leggett BA, Thomas LR, Knight N, Healey S, ChenevixTrench G, Searle J. Exclusion of APC and MCC gene as the gene defect in family with familial juvenile polyposis. Gastroenterology 1993;105:1313-16.

25 Thomas HJW, Whitelaw SC, Cottrell SE, et al. Genetic mapping of the hereditary mixed polyposis syndrome to chromosome 6q. Am f Hum Genet 1996;58:770-6.

26 Farndon PA, Del Mastro RG, Evans DGR, Kilpatrick MW. Location of gene for Gorlin syndrome. Lancet 1992;339: 581-2

27 Chenevix-Trench G, Wicking C, Berkman J, et al. Further localisation of the gene for naevoid basal cell carcinoma syndrome (NBCCS) in 15 Australasian families - linkage and loss of heterozygosity. Am F Hum Genet 1993;53:760-7.

28 Johnson RL, Rothman AL, Xie J, et al. Human homolog of patched, a candidate gene for the basal cell nevus syndrome. patched, a candidate gene

29 Shovlin CL, Hughes JMB, Tuddenham EGD, et al. A gene for hereditary haemorrhagic telangiectasia maps to chromosome 9q3. Nat Genet 1994;6:205-9.

30 Johnson DW, Berg JN, Baldin MA, et al. Mutations in the activin receptor-like kinase 1 gene in hereditary hemorrhagic telangectasis type 2. Nat Genet 1996;13:189-95.

31 Liaw D, Marsh DJ, Li J, et al. Germline mutations of the PTEN gene in Cowden's disease, an inherited breast and thyroid cancer syndrome. Nat Genet 1997;16:64-7.

32 Fargnoli MC, Orlow SJ, Semel-Conception J, Bolognia JL. Clinicopathologic findings in the Bannayan-RileyClinicopathologic findings in the Bannayan-Riley-

33 Marsh DJ, Dahia PLM, Zheng Z, et al. Germline mutations in PTEN are present in Bannayan-Zonana syndrome. Nat Genet 1997;16:333-4.

34 Jacoby RF, Schlack S, Cole CE, et al. A juvenile polyposis tumour suppressor locus at $10 \mathrm{q} 22$ is deleted from nonepithelial cells in the lamina propria. Gastroenterology 1997; 112:1398-403.

35 Jacoby RF, Schlack S, Sekhon G, Laxova R. $\operatorname{Del}(10)(\mathrm{q} 22.3 \mathrm{q} 24.1)$ associated with juvenile polyposis. Am F Med Genet 1997;70:361-4. 